\title{
PRINCÍPIO DA PRECAUÇÃO: DEFINIÇÃO DE BALIZAS PARA A PRUDENTE APLICAÇÃO
}

Romeu Faria Thomé da Silva

Pós-Doutor em Direito pela Université Laval, Canadá. Doutor em Direito pela Pontifícia Universidade Católica de Minas Gerais. Mestre em Direito pela Universidade Federal de Minas Gerais. Professor do Mestrado em Direito Ambiental da Escola Superior Dom Helder Câmara (ESDHC). Email: romeuprof@hotmail.com

Jamile Bergamaschine Mata Diz

Doutora em Direito Comunitário - Universidad de Alcalá - Espanha. Mestre em Instituciones y Políticas de la UE pela UCJC-Madrid. Coordenadora da Cátedra Jean Monnet Direito UFMG. Professora do Mestrado em Direito Ambiental da Escola Superior Dom Helder Câmara (ESDHC). Professora da Faculdade de Direito da UFMG e da Universidade de Itaúna. E-mail: jmatadiz@yahoo.com.br

\section{RESUMO}

O presente trabalho pretende identificar e propor a utilização de critérios de aplicação do princípio da precaução. Constata-se que houve distorções no significado de precaução, abrindo caminho para a sua utilização como fundamento de decisões autoritárias e desprovidas de argumentos cientificamente consistentes, muitas vezes impregnadas de caráter ideológico e subjetivo, acarretando insegurança jurídica. Razoabilidade, proporcionalidade, adoção nos casos de riscos graves e irreversíveis, motivação expressa, reavaliação periódica das decisões e participação da sociedade sob a perspectiva democrática são alguns dos critérios sugeridos para balizar a aplicação do princípio da precaução. A inobservância desses critérios pode acarretar subjetividade nas decisões, passível de suscitar controle tanto no âmbito interno quanto externo. As linhas críticometodológica e jurídico-propositiva foram empregadas na metodologia, pois, a partir do olhar sobre a realidade, buscou-se realizar uma análise crítica capaz de orientar a propositura de critérios de aplicação da precaução sob a luz do Estado Democrático de Direito.

PALAVRAS-CHAVE: Princípio da precaução; Aplicação; Segurança jurídica; Balizas; Definição de critérios. 


\title{
PRECAUTIONARY PRINCIPLE: DEFINITION OF BEACONS FOR
} PRUDENT APPLICATION

\begin{abstract}
The purpose of this article is to identify and propose the use of criteria for the application of the precautionary principle. There were distortions of the meaning of precaution, which opened the way for its use as a basis for authoritarian decisions and without scientifically consistent arguments, often impregnated with ideological and subjective character. Reasonability, proportionality, adoption in cases of serious and irreversible risks, express motivation, periodic reassessment of decisions and participation of society in a democratic perspective are some of the suggested criteria to guide the application of the precautionary principle. The critical-methodological and legal-propositional methods were used. The aim was to perform a critical analysis capable of proposing criteria for applying precaution in the Democratic State of Law.
\end{abstract}

KEYWORDS: Precautionary principle; Application; Beacons; Definition of criteria. 


\section{INTRODUÇÃO}

As origens do princípio da precaução remontam ao início da década de 1970, quando a intensificação da produção industrial gerou questionamentos sobre os riscos das atividades antrópicas sobre a saúde humana e o meio ambiente. A Alemanha e a Suécia são exemplos de países que passaram a exigir a adoção de medidas de precaução por empresas que utilizassem produtos perigosos.

Na década de 1980, acordos e tratados internacionais começaram a inserir o princípio da precaução em seus textos, previsão que motivou diversos países a incluir a precaução em seus ordenamentos jurídicos internos. Além disso, constando expressamente no princípio 15 da Declaração do Rio, documento elaborado no marco da Conferência das Nações Unidas sobre o Meio Ambiente e o Desenvolvimento, em 1992, a precaução se juntou à prevenção no rol de princípios orientados a evitar ou minimizar a concretização de danos ao meio ambiente e à saúde humana.

O princípio da precaução passou então a ser aplicado com maior frequência pelos tribunais nacionais e pelas cortes internacionais, assim como, na esfera administrativa, pelos órgãos públicos responsáveis pelo exercício do poder de polícia ambiental de diversos países. No entanto, em decorrência da diversidade de formulações no âmbito das normas nacionais e internacionais e, também, da ausência de um enunciado único e de pressupostos uniformes para sua aplicação - universalmente aceitos para a precaução - resultaram em interpretações afastadas da percepção que deu origem ao postulado em seu significado originário. Essa nova roupagem do princípio da precaução cuidou de chancelar decisões autoritárias e desprovidas de argumentos cientificamente consistentes. O esvaziamento do sentido da precaução deu causa a situações desarrazoadas e que, não raras vezes, passaram a desafiar a segurança jurídica.

Quais seriam as balizas para orientar a adequada aplicação do princípio da precaução no Estado Democrático de Direito? A presente pesquisa tem como intuito apresentar respostas jurídicas adequadas à referida indagação. O objetivo do trabalho é, portanto, identificar e sugerir a utilização de critérios de aplicação do princípio da precaução.

Impõe-se registrar que atualmente se percebe uma nítida dificuldade de interpretação do princípio da precaução, tanto pelos órgãos da Administração Pública responsáveis pela gestão do patrimônio ambiental, quanto pelos julgadores responsáveis pela análise e decisão definitiva dos 
casos concretos. A ideia nuclear que anima os propósitos da pesquisa sobre a definição de balizas de aplicação do princípio da precaução consiste exatamente na constatação da parcela abstrata ínsita à própria norma jurídica classificada como princípio.

As linhas metodológicas utilizadas foram a crítico-metodológica e a jurídico-propositiva, pois, a partir do olhar sobre a realidade, buscouse desenvolver uma análise crítica capaz de orientar a propositura de critérios claros de aplicação da precaução, que poderão contribuir para o aperfeiçoamento das decisões administrativas e judiciais condizentes com os pilares do Estado Democrático de Direito.

\section{AS ORIGENS E OS OBJETIVOS DO PRINCÍPIO DA PRECAUÇÃO}

O princípio da precaução preconiza a implementação de medidas hábeis a impedir a degradação ambiental, nas situações de perigo de dano grave e irreversível decorrentes de atividades ou técnicas cujos impactos ainda não podem ser claramente identificados pela ciência. A cautela deve orientar as ações do poder público, sempre que houver incerteza científica em relação aos impactos ambientais de determinado empreendimento.

A lei sueca sobre produtos perigosos para o homem e para o meio ambiente, aprovada em 1973, é considerada a primeira a prever a exigência de adoção de medidas de precaução por aqueles que utilizassem produtos perigosos. Todavia, ensinam Varela e Zini (2015), Sampaio (2003) e Wolfrum (2004), que foram os alemães os responsáveis por explicitar o princípio da precaução (die Vorsorgeprinzip) na Lei de Proteção das Águas, que incluía como tarefa estatal prevenir ou reduzir danos ambientais futuros, mesmo na ausência de riscos presentes.

O princípio da precaução, também denominado princípio da cautela, ou da prudência (VARELA; ZINI, 2015), ganha evidência a partir da década de 1980, com a adoção, em acordos e tratados internacionais, de normas orientadas a evitar ou mitigar as emissões de substâncias causadoras de esgarçamento da camada de ozônio do planeta, como o gás clorofluorcarbono (CFC). Gouveia e Freitas Martins (2002) registram que, desde 1976, uma série de países adotou, voluntariamente, medidas tendentes a reduzir a emissão daqueles gases. Lembra Sunstein (2005) que, em 1982, a Carta Mundial das Nações Unidas para a Natureza, aparentemente reconheceu o princípio, ao prever que, enquanto potenciais 
efeitos adversos não forem conhecidos, as atividades não devem ter início. Importa ressaltar, no entanto, que apenas em 1985 foi consolidado o primeiro acordo multilateral sobre o tema, internacionalmente conhecido como Convenção de Viena para a Proteção da Camada de Ozônio. O documento já determinava a adoção de medidas de precaução, com o objetivo de evitar a concretização de danos sobre a camada de ozônio do planeta (THOMÉ, 2014).

Dois anos depois, em setembro de 1987, foi elaborado o Protocolo de Montreal sobre as Substâncias que Destroem a Camada de Ozônio, segundo o qual todos os esforços devem ser envidados para a eliminação da produção e do consumo de gases prejudiciais à camada de ozônio. Seu preâmbulo realça a previsão da necessidade de adoção de mecanismos precaucionais:

\begin{abstract}
Determinados a proteger a camada de ozônio, adotando medidas precaucionais para controlar o volume global de emissões de substâncias que a danificam, o objetivo último é o de eliminá-las com base na evolução dos conhecimentos científicos e tendo em conta considerações técnicas e econômicas, além das necessidades dos países em desenvolvimento em matéria de desenvolvimento. (Tradução nossa). (UNITED NATIONS DEVELOPPEMENT PROGRAM, 2013).
\end{abstract}

A precaução ganha força como princípio do Direito Ambiental no âmbito internacional na Segunda Conferência Internacional sobre proteção do Mar do Norte em 1987, que previa a adoção de medidas orientadas no sentido de incentivar o uso das melhores tecnologias disponíveis nos casos de ausência de provas científicas que atestassem o nexo causal entre emissões de substâncias persistentes, tóxicas e propensas à bioacumulação e aos seus efeitos no oceano (FREITAS MARTINS, 2002; WOLFRUM, 2004).

Mas, é na Conferência das Nações Unidas sobre o Meio Ambiente e o Desenvolvimento, realizada no Rio de Janeiro em 1992, que o princípio da precaução se consolidou como uma garantia contra os riscos potenciais que, de acordo com o estado atual do conhecimento, não podem ser ainda identificados. No caso de ausência da certeza científica formal, a existência do risco de dano sério ou irreversível requer a implementação de medidas que possam prever, minimizar e/ou evitar este dano. De acordo com o princípio quinze da Declaração do Rio de 1992, 
[...] com o fim de proteger o meio ambiente, os Estados deverão aplicar amplamente o critério da precaução, de acordo com suas capacidades. Quando haja perigo de dano grave e irreversível, a falta de certeza científica absoluta não deverá ser utilizada como razão para postergar a adoção de medidas eficazes para impedir a degradação do meio ambiente (NAÇÕES UNIDAS, 1992).

O princípio da precaução foi introduzido no direito comunitário, em 1992, pelo Tratado de Maastricht, também conhecido como Tratado da União Europeia, quando foi alçado ao nível de princípio da política ambiental da União Europeia (MARCIANO; TOURRÈS, 2011).

A Carta Ambiental francesa de 2005 também prevê o princípio da precaução:

\begin{abstract}
Artigo $5^{\circ}$ - Quando a possibilidade de ocorrência de qualquer dano, ainda que incerto o estado do conhecimento científico, possa afetar de maneira grave e irreversível o meio ambiente, as autoridades públicas garantirão, aplicando-se o princípio da precaução em seus campos de atuação, a implementação de procedimentos para a avaliação de riscos e a adoção de medidas provisórias e proporcionais, a fim de evitar a ocorrência do dano. ${ }^{1}$
\end{abstract}

As origens e os objetivos do princípio da precaução foram analisados a partir de uma perspectiva histórica pelo filósofo francês François Ewald (1996). O princípio da precaução resultaria da evolução sequencial de três regimes de organização de responsabilidade social que se sucedem (THOMÉ, 2014).

O primeiro regime, designado Estado-providência, teria sido estruturado a partir do conceito de responsabilidade e culpabilidade individual, vigorando em grande parte do século XIX. O segundo regime, da solidariedade, se desenvolveu durante o século XX, baseado na ideia de solidariedade social. O terceiro regime, por sua vez, está calcado no conceito de segurança, no qual o princípio da precaução apresenta-se como alternativa de gestão da incerteza (EWALD, 1996).

Para o autor francês, o Estado-providência tem a responsabilidade individual e a virtude como pontos focais. Assim, sob o signo do

1 FRANÇA, 2005, tradução nossa. Article 5 - Lorsque la réalisation d'un dommage, bien qu'incertaine en l'état des connaissances scientifiques, pourrait affecter de manière grave et irréversible l'environnement, les autorités publiques veillent, par application du principe de précaution et dans leurs domaines d'attributions, à la mise en oeuvre de procédures d'évaluation des risques et à l'adoption de mesures provisoires et proportionnées afin de parer à la réalisation du dommage. 
individualismo, qualquer ator social pode usar sua liberdade pessoal para agir com prudência. Os perigos e os riscos do dia a dia são assumidos pelos próprios indivíduos, sem qualquer suporte estatal, como decorrência da teoria do liberalismo econômico vigente à época (THOMÉ, 2014).

$\mathrm{Na}$ transição do Estado Liberal para o Social, sob a luz da igualdade, o Estado passou a garantir direitos sociais, incluindo aí o reconhecimento de direito à indenização contra os "perigos da vida". No estado do bem-estar social, esses novos direitos possibilitam a modificação da relação do ser humano com os riscos. Nessa época, o conceito de risco estava diretamente relacionado às situações de insegurança, materialmente perceptíveis, como doenças, miséria e insegurança. A ciência era capaz, até então, de prever os efeitos negativos dos riscos, possibilitando a atuação do Estado (THOMÉ, 2014). Dessa forma, o conceito de responsabilidade assumia a forma de abordagem preventiva, possível em decorrência do conhecimento técnico e científico.

O terceiro período, segundo Ewald (1996), é inaugurado com as questões ambientais nas décadas de 1960 e 1970, gravitando em torno do conceito de "segurança". A coletividade passa a reconhecer a sua vulnerabilidade frente a novos riscos decorrentes das atividades humanas e à falibilidade da ciência para identificá-los e impedi-los. Diferentemente do que verificado no Estado Social, os afetados pelos impactos negativos sobre o meio ambiente têm nova percepção da ideia de dano, agora caracterizado pela sua abrangência, gravidade e irreversibilidade. A ciência passa a sofrer críticas (internas e externas) e o sistema de reparação e de compensação financeira não são mais adequados face às novas características do dano. Passou-se então a perceber a necessidade de evitar a concretização de danos socioambientais.

O princípio da precaução é considerado, assim, como uma garantia contra riscos potenciais que, de acordo com o estado atual do conhecimento, não podem ser ainda identificados (THOMÉ, 2018). Ainda, o princípio da precaução pode ser considerado como um instrumento que reflete uma característica do ser humano: a abordagem precautória, segundo a qual o ser humano visa diminuir os riscos aos quais está exposto (BECK, 2008). Essa abordagem tem surgido como um imperativo da política ambiental. Quando se depara com uma situação em que o efeito do dano é incerto, o princípio da precaução demanda uma postura mais conservadora no que tange à assunção de riscos, devendo, contudo, pautarse em critérios que evitem a insegurança jurídica e a interpretação subjetiva 
e desconexa com a realidade (MATA DIZ; SANTOS, 2016).

Para Édis Milaré (2015, p. 264),

a invocação do princípio da precaução é uma decisão a ser tomada quando a informação científica é insuficiente, inconclusiva ou incerta e haja indicações de que os possíveis efeitos sobre o ambiente, a saúde das pessoas ou dos animais ou da proteção vegetal possam ser potencialmente perigosos e incompatíveis com o nível de proteção escolhido.

Naves e Silva (2014, p. 369) consideram o princípio da precaução uma garantia contra os riscos potenciais que "corresponde ao dever de cautela para com os riscos incertos cientificamente, gerados por uma determinada atividade ou empreendimento".

No ornamento jurídico pátrio, algumas leis referem-se expressamente ao princípio da precaução, tais como a Lei de Biossegurança (Lei 11.105/2005), que elenca como diretrizes, em seu artigo 10 "o estímulo ao avanço científico na área de biossegurança e biotecnologia, a proteção à vida e à saúde humana, animal e vegetal, e a observância do princípio da precaução para a proteção do meio ambiente", e a Lei de Política Nacional sobre Mudança do Clima (Lei 12.187/2009) que, nos termos do seu artigo $3^{\circ}$, deverá observar "os princípios da precaução, da prevenção, da participação cidadã, do desenvolvimento sustentável e o das responsabilidades comuns, porém diferenciadas (...).” A Lei 12.608/2012 (Lei de desastres ambientais), no $\S 2^{\circ}$ do seu artigo $2^{\circ}$, refere-se implicitamente ao princípio da precaução, ao dispor que "a incerteza quanto ao risco de desastre não constituirá óbice para a adoção das medidas preventivas e mitigadoras da situação de risco."

Com a sua consolidação a partir da década de 1990, o princípio da precaução passa a ser utilizado e invocado com maior frequência, tanto no ordenamento jurídico de inúmeros países quanto nas cortes internacionais, como a Corte Internacional de Justiça, o Tribunal Internacional do Direito do Mar e o Tribunal de Justiça da União Europeia (SUNSTEIN, 2005). As discussões em relação aos impactos ainda desconhecidos ao meio ambiente e à saúde humana, como as que envolveram as decisões da Organização Mundial do Comércio - OMC no caso da carne com hormônios $^{2}$ do Conseil d'État français, relativa à comercialização do

2 Na decisão do Órgão de Apelação criado para decidir este caso, houve intenso debate em relação à categorização da precaução como princípio geral de direito, já que “[o]status do princípio da precaução no direito internacional permanece objeto de debate entre estudiosos, operadores do Direito, reguladores e juízes. Há quem considere que o princípio da precaução tenha se cristalizado em princípio geral consuetudinário do direito ambiental internacional. A questão se o princípio foi aceito pelos Membros 
milho geneticamente modificado (BOISSON DE CHAZOURNES, 1999) ou ainda da decisão do Tribunal de Justiça da União Europeia, no caso da encefalopatia espongiforme bovina (também conhecido como caso das "vacas loucas", 1998) proporcionaram acalorados debates relacionados aos limites de aplicação do princípio da precaução.

No âmbito nacional, algumas decisões dos tribunais superiores também adotaram o princípio da precaução como alicerce de sustentação, como nos julgados do Supremo Tribunal Federal (STF) na arguição de descumprimento de preceito fundamental 101 (2009) e na ação declaratória de inconstitucionalidade 3540 (2010) ou do Superior Tribunal de Justiça, nos recursos especiais 972.902 e 1.060.753, ambos publicados em 2009 .

A análise de decisões judiciais e administrativas, nacionais e internacionais, conduz à conclusão de que, nos últimos anos, as contendas se intensificaram. Percebem-se, a luzes claras, nítidas distorções na interpretação do princípio da precaução, fato que tem o condão de interferir negativamente na sua função primária de implementação do desenvolvimento sustentável.

Não remanescem dúvidas acerca da relevância do princípio da precaução para o Direito Ambiental. Mas, sua notabilidade não pode conduzir o intérprete a invocá-lo, indiscriminadamente, a toda e qualquer modalidade de situação na qual esteja presente risco ao meio ambiente. A sua incidência só se legitima quando se encontra balizada em critérios preestabelecidos e, ainda, atendendo-se a certos limites, sob pena de desvirtuamento de seus objetivos normogenéticos e de sua consequente banalização, o que acarretaria sua inaplicabilidade por esvaziamento.

\section{ANÁLISE CRÍTICA DO PRINCÍPIO DA PRECAUÇÃO}

Inicialmente, é importante observar que considerável parcela das distorções do significado se deve ao fato de o princípio da precaução ter sido objeto de inúmeras formulações no âmbito das normas nacionais e internacionais. Inexiste um enunciado único e uma interpretação uniforme, universalmente aceitos para a precaução, o que dificulta a sua compreensão

como um princípio geral ou consuetudinário do direito internacional parece ainda menos clara. Consideramos, entretanto, que é desnecessário, e provavelmente imprudente, que o Órgão de Apelação, nesta controvérsia, posicione-se com relação a esta questão importante, mas abstrata. Apontamos que o Grupo Especial não tomou decisão definitiva no que diz respeito ao status do princípio da precaução no direito internacional e que o princípio da precaução, pelo menos fora do âmbito do direito internacional ambiental, ainda aguarda por uma formulação de órgão com mais autoridade neste domínio" (WORLD TRADE ORGANIZATION, 1998, p.45 para 123, tradução nossa)." 
e, consequentemente, a sua aplicação aos casos concretos. Adverte Antunes (2016, p. 68) que a sua desmedida expansão e "a sua indefinição conceitual são elementos desestabilizadores da ordem jurídica, (...) exatamente o contrário do que se espera de um princípio jurídico".

Ademais, não raras vezes, é possível perceber uma confusão conceitual entre o princípio da precaução e o princípio da responsabilidade, idealizado por Hans Jonas (2006). O princípio da precaução, analisado a partir de dados científicos e de uma lógica de verossimilhança, deve ser entendido numa perspectiva concreta de gestão de riscos, baseada no nexo de causalidade existente entre a atividade e o risco de dano grave e irreversível ao meio ambiente. O princípio da responsabilidade, por sua vez, flerta com o abstrato, pois foi construído como exercício de antecipação a longo prazo. Ele, certamente, apresentará uma decisão interessante do ponto de vista ideal, mas que, na maioria das vezes,será pragmaticamente insustentável.

Para Marciano e Tourrés (2011), o princípio da responsabilidade busca o desejável em nome de uma ética da prudência, mas não se enquadra nas hipóteses passíveis de judicialização, apresentando-se inadequado para fundamentar uma ação na justiça. O princípio da responsabilidade não é, segundo os autores, passível de previsão em norma jurídica.

Enquanto o princípio da responsabilidade tem maior alcance e amplitude, o princípio da precaução guarda objetivos práticos e bem definidos. Ele se ocupa do meio ambiente e da saúde humana, quase sempre interligados, não se ocupando de voos mais altos, metafísicos, relacionados à preservação da existência humana e à sua autenticidade.

Não seria absurdo afirmar que o princípio da responsabilidade funciona como uma bússola em relação ao princípio da precaução. Todavia, não há dúvidas em relação à diferença existente entre eles, ainda que alguns insistam em relacioná-los e, até mesmo, (con)fundi-los. Seus objetivos e seu modo de aplicação são distintos. Tão dessemelhantes que o idealizador do princípio da responsabilidade, Hans Jonas, não abordou, em seu livro, o princípio da precaução (Vorsorgeprinzip). Omissão surpreendente (e coerente), observam Marciano e Tourrès (2011), pois, no momento da publicação da obra (1979), as questões relacionadas ao princípio da precaução já eram debatidas havia anos, na Alemanha.

Além da confusão com o princípio da responsabilidade, verifica-se que o princípio da precaução vem sendo utilizado, com grande frequência, como fundamento de decisões autoritárias e desprovidas de 
argumentos cientificamente consistentes. Ao reconhecer o excesso de sua utilização nos dias atuais, afirma o Supremo Tribunal Federal que o princípio da precaução

não é absoluto, e o exagero em sua aplicação tem gerado reclamações não só na Comunidade Europeia, mas, em todo o mundo. Kenneth R. Foster, professor do Departamento de Bioengenharia da Universidade da Pensilvânia (EUA), em seu célebre artigo intitulado O Princípio da Precaução: bom senso ou extremismo ambiental (The Precautionary Principle: Commonsense or Devil's Handwork? Sigma Xi, Newark NJ,February 2002), advertiu quanto à existência de inúmeras divergências sobre o conteúdo do princípio e a extensão de seus efeitos, o que estaria a trazer problemas aos Estados europeus, em especial, à França, onde sua aplicação, em muitos casos, tinha como real objetivo fazer valer um protecionismo comercial ou, então, acabava sendo utilizado simplesmente como um fator discursivo de cunho político ou sociológico por pessoas normalmente contrárias a mudanças. Esse autor, inclusive, relembrando os "sete aspectos escorregadios da precaução" a que, originariamente, se referiu David Vander Zwaag, eminente pesquisador canadense e especialista em direito ambiental (vide artigo publicado na página eletrônica da Social Science Research Network, The Precautionary Principle and Marine Environmental Protection: Slippery Shores, Rough Seas, anda Rising Normative Tides (2002). 33 (2) Ocean Development \& International Law, 165), chega a advertir que o princípio ainda permanece flexível em sua definição (BRASIL, 2016).

Essa lacuna conceitual proporciona margem à utilização do princípio da precaução como justificativa para a tomada de decisões arbitrárias e desproporcionais, muitas vezes impregnadas de caráter ideológico e subjetivo. "A inexistência de diretrizes operacionais para a aplicação do princípio da precaução transmuta-o de instrumento de gestão de riscos em mera álea", salienta Antunes (2016, p. 74).

Essas distorções dão azo a situações de insegurança jurídica que podem e devem ser corrigidas com a adoção de critérios e balizas direcionadas à aplicação do princípio da precaução, em consonância com o princípio do desenvolvimento sustentável e com o Estado Democrático de Direito.

3 DEFINIÇÃO DE BALIZAS PARAAAPLICAÇÃO DO PRINCÍPIO DA PRECAUÇÃO

Não obstante a relevância da adoção de mecanismos precaucionais 
para evitar, ou, ao menos, minimizar, danos irreversíveis ao meio ambiente, entende-se a necessidade de se definir balizas claras de aplicação desse princípio.

Para que a atuação do Poder Público seja considerada legítima, uma gama de limitações e de diretrizes impostas pela atual relação instaurada entre o Estado e o particular há de ser observada, em respeito aos postulados do Estado Democrático de Direito (THOMÉ, 2013). No âmbito da aplicação das normas de proteção ambiental, tais balizas devem também estar bem delimitadas, sobretudo nas questões que envolvem restrição ou limitação do desenvolvimento de determinadas atividades, tecnologias ou empreendimentos.

Sem a pretensão de esgotar o tema, serão analisadas a seguir algumas alternativas para ajustar a aplicação do princípio da precaução às prerrogativas do Estado Democrático de Direito.

\subsection{Riscos graves e irreversíveis}

Nem todos os riscos demandam a aplicação de medidas de precaução, mas apenas os considerados graves e irreversíveis, ou seja, aqueles estimados como os mais perigosos à saúde humana e ao meio ambiente. A aplicação do princípio da precaução pressupõe, portanto, que sejam vencidas duas etapas distintas e sucessivas: I) a identificação da existência de risco; II) a caracterização do risco como grave e irreversível.

Vale lembrar que toda atividade humana gera algum tipo de risco à saúde humana ou ao meio ambiente, inexistindo um nível zero de risco ou de impacto. Assim, aplicar o princípio da precaução a todo e qualquer tipo de risco originado de atividades antrópicas impediria o avanço científico e tecnológico. Sampaio (2003, p. 60), ao analisar as diversas interpretações do princípio, observa que a precaução, na sua concepção forte, mais rigorosa, "pode levar à conclusão de que nenhuma nova tecnologia, atividade ou produto atenderá à exigência da precaução".

A aplicação do princípio da precaução não tem como objetivo, portanto, estabelecer um nível zero de risco ambiental (meta inalcançável), mas gerenciar os riscos graves e irreversíveis decorrentes das atividades humanas. Para Gullet (2000), o princípio da precaução não advoga uma política de risco zero; apenas exige que seja dada a devida importância à proteção da saúde pública e do meio ambiente, sempre que o número de 
informação científica disponível for insuficiente para uma segura tomada de decisão. Portanto, este critério, per se, e aplicado de forma individual, não deve ser considerado como único fundamento a amparar a aplicação da precaução.

Nesse mesmo sentido ocorre o entendimento do Supremo Tribunal Federal (2016), ao afirmar que

(...) não se mostra correta a afirmativa de que esse princípio deva ser aplicado quando não comprovado o afastamento total dos riscos efetivos ou potenciais. Isso porque penso que, dificilmente, existirá um produto ou serviço que possa estar livre de qualquer margem de risco à saúde ou, conforme o caso, ao meio ambiente.

Na decisão do Recurso Extraordinário 627.189, em 2016, o STF também destaca o precedente da Corte de Justiça da Comunidade Europeia de 2002 (Case C-241-01), segundo a qual as medidas de precaução não devem ser uma tentativa de se atingir um "risco zero", nem podem justificar a adoção de decisões arbitrárias (BRASIL, 2016).

É necessário, portanto, situar o princípio da precaução no atual estágio de relativismo de conhecimento científico contemporâneo. Uma vez admitidos os limites da ciência, incluindo a incapacidade dos cientistas para analisarem os riscos de determinadas atividades ao meio ambiente, não se traduziria tal incapacidade em uma dúvida paralisante, caso o princípio da precaução fosse aplicado a todo e qualquer tipo de risco? Como provar que uma atividade ou uma ação não é suscetível de causar qualquer tipo de risco ao meio ambiente?

Diversos tribunais, nacionais e internacionais, já concluíram que a prudência deve pautar a aplicação do princípio da precaução.

$\mathrm{Na}$ célebre decisão do caso Gabcikovo versus Nagimaros, de 25 de setembro de 1997, a Corte Internacional de Justiça-CIJ levou em consideração o princípio da precaução, mas, não foi além disso. Na decisão, que analisou a violação recíproca de regras referentes à utilização do Rio Danúbio pela Eslováquia e Hungria, a corte reconheceu que as partes estavam de acordo sobre a necessidade de se preocupar seriamente com o meio ambiente e de adotar todas as medidas de precaução necessárias, mas que estavam fundamentalmente em desacordo sobre as consequências e riscos que poderiam decorrer do projeto em conjunto (construção e funcionamento de um sistema de barragens hidráulico), o que tornava inviável a aplicação da precaução ao caso concreto. 
Já em 2010, na decisão do "Caso das Papeleras", em que figuraram como partes a República Argentina e a República do Uruguai, a Corte Internacional de Justiça, assim como no caso Gabcikovo versus Nagimaros, levou em consideração o princípio da precaução sem, todavia, aplicá-lo de maneira contundente. No caso em tela, segundo a Argentina, o Uruguai teria violado obrigações decorrentes do Estatuto do Rio Uruguai, assinado por ambos os países em fevereiro de 1975. De acordo com o requerimento argentino, a violação ao estatuto resultaria de eventual início de operação de duas usinas papeleiras instaladas no Rio Uruguai, que teria originado efeitos negativos sobre a qualidade das águas daquele rio e de sua zona de influência.

A decisão da CIJ, que teve como mérito reconhecer a avaliação de impacto ambiental como objeto de costume internacional (TOLEDO, RIBEIRO, THOMÉ, 2016), não aplicou o princípio da precaução para a inversão do ônus da prova, solicitado pela Argentina. A Corte considerou que, se, por um lado, a abordagem da precaução pode se mostrar pertinente para a interpretação e aplicação de algumas disposições do Estatuto de 1975, por outro, não tem por efeito operar a inversão do ônus da prova. Além disso, conclui-se da decisão que a CIJ não foi convencida pela Argentina sobre a inobservância, por parte do Uruguai, do princípio da precaução.

No Brasil, o Supremo Tribunal Federal, reconhecendo a impossibilidade de aplicação do princípio da precaução a qualquer tipo de risco decorrente das atividades antrópicas, considera "que a existência dos referidos riscos decorrentes de incertezas científicas não deve produzir uma paralisia estatal ou da sociedade."

Nas tomadas de decisão, o poder público deve levar em consideração, portanto, que o princípio da precaução não é aplicável a qualquer tipo de risco ao meio ambiente ou à saúde humana, mas que incide apenas nos casos de riscos de danos significativos e irreversíveis (PARGA; MASEDA, 2001).

\subsection{Razoabilidade e proporcionalidade}

A partir da Constituição Federal de 1988, a relação instaurada entre o Estado e o particular torna-se mais dialógica e menos impositiva, sob a luz dos direitos fundamentais e da participação popular que limitam a atuação estatal. Com a consolidação do Estado Democrático de Direito, 
surge a necessidade de revisão das categorias clássicas do Direito Administrativo e de uma nova abordagem da atuação estatal (THOMÉ, 2013).

Para Justen Filho (2006, p. 18), "no Brasil, em especial, é imperioso destacar a necessidade de revisão do direito administrativo, que ainda está entranhado de concepções não democráticas, provenientes do passado." O autor enfatiza, ainda, que

a atividade administrativa estatal continua a refletir concepções personalistas de poder, em que o governante pretende imprimir sua vontade pessoal como critério de validade dos atos administrativos e invocar projetos individuais como fundamento de legitimação para a dominação exercitada (JUSTEN FILHO, 2006, p. 18).

A atuação do Poder Público baseada nos pilares do autoritarismo outrora vigente, passível de afetar a esfera de direitos de liberdade e propriedade do cidadão, passa a ser considerada conduta flagrantemente ilegítima.

A discricionariedade da Administração Pública, durante muito tempo considerada absoluta e intangível, é gradativamente substituída pela noção de liberdade vinculada e justificável racionalmente. Afirma Freitas (2004, p. 26) que "toda discricionariedade (no plano dos mandamentos Tatbestand - ou na eleição das consequências) resta vinculada aos princípios fundamentais, donde se extrai a inexistência de discricionariedade pura".

Para serem considerados legítimos, exige-se a justificativa expressa dos atos da Administração Pública. As regras administrativas devem estar sempre em consonância com os princípios fundamentais garantidos constitucionalmente, não devendo os agentes públicos acatar mandamentos violadores desses princípios (THOMÉ, 2013).

Freitas (2004) enuncia ainda alguns princípios fundamentais que devem reger as relações de administração no Brasil, destacando-se, dentre eles, o princípio da proporcionalidade ou da adequação axiológica e da simultânea vedação de excesso e de inoperância.

O princípio da proporcionalidade (adequação, necessidade e proporcionalidade em sentido estrito) apresenta-se como imprescindível instrumento limitador dos atos do Poder Público, sobretudo dos atos decorrentes do poder de polícia administrativa, uma vez que estabelece parâmetros de avaliação e controle, podendo ser utilizado para forçar a revisão dos atos estatais. 
O princípio da proporcionalidade, ou da proibição do excesso, diz respeito, originariamente, à limitação do Poder Executivo, e é tido como medida para as restrições administrativas da liberdade individual. Afirma Canotilho (2003, p. 267) que "o princípio da proporcionalidade em sentido amplo, também conhecido por princípio da proibição de excesso (Übermassverbot), foi erigido à dignidade de princípio constitucional" em diversos países.

Para Canotilho (2003, p. 268), "através de standards jurisprudenciais como o da proporcionalidade, razoabilidade, proibição de excesso, é possível hoje recolocar a administração (e, de um modo geral, os poderes públicos) num plano menos sobranceiro e incontestado relativamente ao cidadão".

Importante observar que o campo de aplicação mais relevante do princípio da proibição de excesso é o da restrição de direitos, liberdades e garantias por atos do Poder Público, sejam eles emanados pelo Poder Legislativo, Executivo ou Judiciário. Vale lembrar, ainda, que a Administração Pública deve sempre observância ao princípio da vedação de excesso, principalmente nos casos em que dispõe de espaços de discricionariedade em suas decisões (CANOTILHO, 2003, p. 272).

Os atos da Administração Pública devem obedecer ao princípio da proporcionalidade em sua tríplice dimensão (adequação, necessidade e proporcionalidade em sentido estrito). Para Freitas (2004, p. 245),

a limitação administrativa deve ser consentânea com o vetusto princípio da proporcionalidade, que passou a ser adotado como versão da complexa noção de justo meio (mesotes) de Aristóteles. (...) Exprimindo de modo sugestivo o cerne de princípio, Fritz Fleiner, fazendo coro com Walter Jellinek proclamava: "a polícia não deve utilizar canhões para abater pardais".

A aplicação do princípio da precaução, tanto pela Administração Pública quanto pelo Poder Judiciário, deve observar, por óbvio, os requisitos da proporcionalidade e razoabilidade. Aplicar a precaução não significa, como entendem alguns, banir ad aeternum qualquer tipo de atividade ou empreendimento que represente algum risco ao meio ambiente ou à saúde humana. A falta de certeza científica é motivo para que se adotem medidas de proteção ambiental. Essas medidas, vale lembrar, podem ser também de cunho restritivo (nem sempre de cunho proibitivo). Ao se restringir o plantio de organismos geneticamente modificados a certas áreas 
previamente aprovadas pelo poder público, aplica-se, também, o princípio da precaução.

Entende o Supremo Tribunal Federal (2016) que

Havendo relevantes elementos de convicção sobre os riscos, o Estado há de agir de forma proporcional. Sua adequada aplicação na dimensão material deve propiciar que a investigação dos riscos ocorra sobre as "consequências distantes tanto em tempo como em lugar, [sobre] danos a bens particularmente sensíveis, [sobre] meros distúrbios e até [sobre a] pouca probabilidade de danos", de forma a propiciar a adoção de medidas pertinentes e proporcionais (cf. Gerd Winter. A Natureza Jurídica dos Princípios Ambientais em Direito Internacional. In, KISHI, Sandra A. S., SILVA, Solange T. Da e SOARES, Inês V. P. (Org.). Desafios do Direito Ambiental no Século XXI. São Paulo: Malheiros, 2005, p. 144).

O excesso na aplicação da precaução pode significar, em determinadas situações, o surgimento de novos riscos ao meio ambiente e à saúde humana e, até mesmo, acarretar danos indenizáveis a terceiros. Sunstein (2005, p. 33) alerta que "o Estado precisa agir com precaução, na sua versão balanceada, apenas quando tiver motivos idôneos a ensejar uma intervenção antecipatória proporcional, nos limites da tessitura normativa. Se não o fizer, aí sim, será partícipe da geração de dano irreversível ou de difícil reparação".

A Comissão da União Europeia, com o intuito de orientar a tomada de decisões com base no princípio da precaução, indica como elementos a serem observados quando estiver envolvida a gestão de riscos: a) a proporcionalidade entre as medidas adotadas e o nível de proteção escolhido; b) a não discriminação na aplicação das medidas; c) e a coerência das medidas que se pretende tomar com as já adotadas em situações similares ou que utilizem abordagens similares (BRASIL, 2016).

Entende o STF (BRASIL, 2016) que a adoção do critério da proporcionalidade é essencial para o equacionamento adequado dos elementos que levam a administração pública a agir e a implementar medidas acautelatórias.

Vale lembrar que a aplicação do princípio da precaução é passível de controle administrativo e jurisdicional, sobretudo no que tange à avaliação dos limites legais da discricionariedade e à observância da proporcionalidade na medida protetiva adotada. 


\subsection{Motivação expressa e fundamentação}

A comprovação da verossimilhança das alegações deve ser pressuposto para a adoção do princípio da precaução nas decisões relacionadas às questões ambientais. Não se pode admitir uma decisão, seja ela administrativa ou judicial, fundada apenas em alegações levianas que tenham hipóteses de causalidade estabelecidas por via dedutiva. Medidas precaucionais não podem ser adotadas com base em hipotéticas alegações de risco, fundadas em meras conjecturas sem qualquer verificação científica.

Marciano e Tourrès (2011) destacam que a lógica indiciária não é da mesma ordem de rigor da causalidade tradicional. Todavia, ela não resulta da pura subjetividade, mas da probabilidade, seja a partir daquilo que pareça verdadeiro, seja do feixe convergente de dados disponíveis, capaz de fortalecer a hipótese emitida na síntese dessas pistas.

Ao reconhecer a necessidade de fundamentação legal fundada em juízo de verossimilhança para sua a aplicação, afirma o Supremo Tribunal Federal (BRASIL, 2016) que

\footnotetext{
o princípio da precaução, dotado de eficácia direta, impõe ao Estado Democrático de Direito um conjunto de diligências não tergiversáveis, no sentido de que a obrigação de resguardar, de garantir o direito fundamental ao meio ambiente sadio, ocorrerá com a adoção de medidas proporcionais, ainda nos casos de incerteza quanto à produção de danos fundamentadamente temidos, ou seja, em havendo juízo de verossimilhança.
}

Assim, os riscos graves e irreversíveis decorrentes da falta de certeza absoluta em relação aos impactos negativos de uma atividade devem ser apontados, em cada caso concreto, objetivamente, sob pena de se tornar uma discussão teórica e abstrata mais afeita ao princípio responsabilidade, e não ao princípio da precaução.

Existe, portanto, a possibilidade de controle judicial de políticas públicas fundadas no princípio da precaução, desde que seja possível analisar concretamente os elementos que justificaram a sua aplicação. Nesse sentido é o entendimento do Supremo Tribunal Federal, ao afirmar que "não há vedação ao controle jurisdicional das políticas públicas quanto à aplicação do princípio da precaução, desde que a decisão judicial não se afaste da análise formal dos limites desse conceito e que privilegie a opção democrática das escolhas discricionárias feitas pelo legislador e pela 
Administração Pública" (BRASIL, 2016).

\subsection{A perspectiva democrática da precaução}

A análise dos diversos modelos de Estado possibilita inferir que o Estado Democrático de Direito é aquele que assegura a participação popular e o controle social desde a elaboração até a implementação das políticas públicas, reconhecendo-se como elemento fundante para a própria concepção de Estado. Os instrumentos democráticos passaram a ser gradativamente mais utilizados com o objetivo de oportunizar a atuação efetiva da sociedade no exercício do poder. Os agentes públicos, que exercem diretamente o poder político, passam a ser aqueles representantes diretos do povo, por ele escolhidos. Com isso, os direitos garantidos no mero Estado de Direito foram ampliados (THOMÉ, 2014).

No Estado de Direito verifica-se a limitação da atuação do Poder Público a partir do império do direito, da observância das normas jurídicas também pelo Estado (THOMÉ, 2014). As ideias do "governo de leis e não de homens" foi implementada por institutos como os de Ruleoflaw, Always underlaw, Rechsstaat, dentre outros. No entanto, salienta Canotilho (2003, p. 98), "alguma coisa faltava ao Estado de direito constitucional - a legitimação democrática do poder".

Para Sundfeld (2012), o Estado Democrático de Direito engloba as noções de constitucionalismo, participação popular direta, separação de poderes, legalidade e direitos individuais e políticos.

No Brasil, a partir da Constituição Federal de 1988, a relação entre Estado e cidadão tornou-se mais dialógica e menos impositiva. Não há dúvidas de que o princípio democrático pressupõe a fragmentação da ideia de supremacia da Administração Pública, ideia esta impregnada na relação Estado-cidadão desde o século XIX e grande parte do século XX (FREITAS, 2004).

Para Marciano e Tourrès (2011), o princípio da responsabilidade, de Hans Jonas, é insustentável democraticamente, uma vez que ele não se abre para discussão no espaço público. A falta de lucidez atribuída ao povo por Jonas justifica no princípio da responsabilidade o advento de uma "tirania benevolente", conduzida por um pequeno número de "sábios" ou "experts". Ao criticar o posicionamento de Jonas, os autores defendem que, em respeito ao princípio democrático, o "viver junto" exige que os riscos sejam aceitos ou descartados "em conjunto". 
O princípio da precaução, por sua vez, partindo de uma lógica de verossimilhança e, portanto, do comensurável, produz argumentos que a esfera política pode debater no âmbito da sociedade, ou seja, na esfera democrática. O princípio da precaução não deve ser utilizado, portanto, como fundamento de decisões autoritárias e desprovidas de argumentos cientificamente consistentes, inadmissíveis no Estado Democrático de Direito. Neste sentido, a participação nas decisões relativas ao meio ambiente e à saúde humana tornam-se corolário inafastável da concepção de democracia, especialmente quando se trata de promover a dialogicidade na relação público-privada

A "tirania benevolente", segundo Hans Jonas (2006), perfaz-se inevitável, tendo em vista a urgência ambiental na qual nos encontramos; e a falta de lucidez ou de vontade dos cidadãos é ínsita ao princípio da responsabilidade, mas não se adequa ao princípio da precaução, que exige o debate democrático. Essa deliberação pressupõe a reavaliação periódica das decisões tomadas a partir da ideia de precaução.

\subsection{Necessidade de reavaliação periódica das decisões tomadas com base na precaução}

A transitoriedade é intrínseca ao princípio da precaução, o que realça ainda mais o seu objetivo de gestão de riscos. Louis-Marie Houdebine, citado por Tourrès e Marciano (2011), ao investigar as bases do princípio da precaução, afirma que ele deve ser aplicado a novas atividades e tecnologias potencialmente geradoras de riscos graves que ainda não podem ser demonstrados pela ciência. Todavia, adverte que a interrupção de atividades com fundamento na precaução deve ser temporária, tornando-se necessária a realização de revisões periódicas do conhecimento científico, para que não reste configurado um período de espera estéril. Desta forma, ao fim do período de "quarentena", o Poder Público deve se posicionar, favorável ou contrariamente, à continuidade daquela atividade, fundamentando sua decisão com base nos estudos científicos e debates populares desenvolvidos durante aquele período de tempo (THOMÉ, 2014).

Fica expressamente estipulado que esse príncipio deve ser aplicado apenas durante períodos limitados de tempo e a um custo razoável para a sociedade. A aplicação do princípio da precaução implica numa interrupção do desenvolvimento ou da 
implementação de uma técnica. Durante este período de tempo, os estudos devem ser realizados no sentido de tentar avaliar os riscos da atividade. No final deste período, uma decisão deve ser tomada, seja no sentido da continuidade da investigação e da quarentena, seja no sentido de se autorizar a implementação da nova técnica. Em hipótese alguma o princípio de precaução deve representar um período de espera estéril (HOUDEBINE, apud TOURRÈS; MARCIANO, 2011, p. 37) .

O alemão Rüdiger Wolfrum (2004, p. 20) também entende que, "se uma atividade foi proibida ou restrita com base no princípio da precaução, a incerteza sob a qual esta decisão foi tomada deve ser reanalisada em intervalos regulares. As novas descobertas, assim como os novos desenvolvimentos, devem ser levadas em consideração".

A análise dos riscos ao meio ambiente não deve conduzir, portanto, a uma decisão imutável, inquestionável e definitiva. Afinal, as descobertas científicas revestem-se do manto da transitoriedade. Entende Thomé (2014, p. 203) que

a ideia nuclear que anima os propósitos do princípio da precaução é a de que os riscos possam ser, durante um lapso de tempo razoável, avaliados, levando-se em consideração as mais diversas e transdisciplinares variantes, trazidas tanto pela comunidade científica, quanto pela sociedade e órgãos democraticamente legitimados.

Assim, haverá elementos capazes de auxiliar e fundamentar a tomada de decisão em relação às atividades potencialmente causadoras de riscos graves e irreversíveis ao meio ambiente.

Nesse mesmo sentidoé o entendimento do Conseil Constitutionnel francês que, ao analisar a aplicação do princípio da precaução para o estabelecimento de disposições permanentes, proibindo qualquer método de faturamento hidráulico de rocha para a exploração e exploração de minas de hidrocarbonetos líquidos ou gasosos (gás de xisto), afirmou que "as autoridades públicas assegurarão, através da aplicação do princípio da precaução e nos domínios das suas competências, a aplicação de

3 HOUDEBINE, apud TOURRÈS; MARCIANO, 2011, p. 37, tradução nossa. Il est expressément stipulé que ce príncipe ne doit être appliqué que pendant des temps limites et à un coût raisonnable pour la société. L'application du principe de précaution implique un arrêt du développement ou de la mise en oeuvre d'une technique. Pendant ce moratoire, des études doivent être menées pour tenter d'évaluer les risques que l'on redoute. À la fin de cette période, une décision doit être prise pour poursuivre les recherches et le moratoire ou de les arrêter pour autoriser la mise en oeuvre de la nouvelle tecnique ou au contraire de l'interdire. En aucun cas, le principe de précaution doit représenter une période d'attente stérile. 
procedimentos de avaliação dos riscos e a adoção de medidas provisórias e proporcionais, a fim de evitar a ocorrência dos danos"'4 (tradução nossa) (FRANÇA, 2018).

Restou claro que o Conselho Constitucional da França se recusou a considerar que a precaução seja um princípio capaz de embasar normas constitucionais que introduzam medidas que não sejam provisórias e temporárias (vide decisões n. 2013-346 QPC de 11 de outubro de 2013 e n. 2014-694 CD de 28 de maio de 2014 do Conseil Constitutionnel).

Andou bem o Supremo Tribunal Federal (BRASIL, 2016) ao reconhecer a precaução como um componente da gestão de riscos, além de reconhecer a existência da verificação de certos pressupostos para a sua adoção nos casos concretos, sendo um deles o de que "a decisão adotada há de se sujeitar a uma revisão sempre que obtidos novos dados científicos".

Ao decidir o Recurso Extraordinário 627.189/SP, em 2016, o STFfaz menção a um documento elaborado pela Comissão Europeia $(\mathrm{COM} / 2000 / 0001)^{5}$ que, com o objetivo de evitar excesso de abstração e de subjetivismo na compreensão do princípio da precaução, e com o fito de evitar decisões discriminatórias ou incoerentes sobre as medidas de controle dos impactos de determinadas atividades sobre o meio ambiente, sugere a adoção das seguintes premissas consideradas como elementos conceituais do princípio da precaução: a) o princípio é um componente de gestão de riscos; b) a decisão política de atuar ou não há de decorrer da consciência da instância decisória sobre o grau de incerteza relativo aos resultados da avaliação dos dados científicos disponíveis; e, c) na hipótese de se decidir por atuar, as medidas a serem adotadas devem respeitar alguns pressupostos específicos.

Os pressupostos apontados pela Comissão da União Europeia e reconhecidos pelo STF representam balizas adequadas para o direcionamento da aplicação do princípio da precaução:

a) devem as medidas ser proporcionais ao nível de proteção escolhido; b) respeito
à não discriminação na sua aplicação; c) o Estado que impõe como requisito
uma aprovação administrativa prévia aos produtos e serviços que considere

4 “(...) les autorités publiques veillent, par application du principe de précaution et dans leurs domaines d'attributions, à la mise en œuvre de procédures d'évaluation des risques et à l'adoption de mesures provisoires et proportionnées afin de parer à la réalisation du dommage".

5 COMISSAO EUROPEIA. Comunicação da Comissão relativa ao princípio da precaução. Bruxelas, 2.2.2000 - COM (2000) 1 final, disponível em https://eur-lex.europa.eu/legal-content/PT/TXT/PDF/? uri=CELEX:52000DC0001\& from=PT, acesso em $03 \mathrm{dez} 2013$. 
perigosos, a priori, deve inverter o ônus da prova, considerando-os perigosos até que os interessados desenvolvam trabalho científico necessário a demonstrar o preenchimento do requisito da segurança e, caso o Estado não exija a referida autorização prévia, caberá às autoridades públicas ou ao interessado demonstrar o nível de risco (para uma aprovação a posteriori); d) permanente exigência de que sejam oferecidos pelos interessados embasamentos científicos para a análise das potenciais vantagens e encargos para a ação ou inação; e) ações coerentes com as medidas semelhantes já tomadas; f) a decisão adotada há de se sujeitar a uma revisão sempre que obtidos novos dados científicos (COMISSÃO DA UNIÃO EUROPEIA apud BRASIL, 2016).

Como se percebe, as singularidades de que se reveste o princípio da precaução impõem ao Estado a observância de pressupostos para uma atuação leal e coerente com as conclusões científicas vigentes na época de sua prática, sem prejuízo da possibilidade de revisão em seu conteúdo, sempre que novos dados científicos assim orientarem. Essa reavaliação periódica legitima a precaução em sua perspectiva da atualidade do grau de certeza científica, elemento que lhe é indissociável.

\section{CONCLUSÃO}

Não remanescem dúvidas de que evitar ou mitigar a concretização de danos ao meio ambiente consiste no objetivo primário das normas ambientais, tendo em vista a hercúlea tarefa de repará-lo após a verificação de sua degradação. Nesse contexto, assumem relevância os princípios da prevenção e da precaução, importantes instrumentos de gestão de riscos socioambientais.

O princípio da precaução, considerado uma garantia contra riscos potenciais que, de acordo com o estado atual do conhecimento, não podem ser ainda identificados, teve sua origem em normas suecas e alemãs, na década de 1970, passando então a ser incluído em tratados internacionais e no ordenamento jurídico interno de inúmeros países.

Em que pese a relevância dos objetivos do princípio da precaução, em virtude das variações conceituais e da ausência de um enunciado único e de uma interpretação uniforme, foram operadas distorções em seu significado, que resultaram em decisões administrativas e judiciais dissociadas da atuação esperada em Estados Democráticos de Direito.

O presente trabalho busca retomar o debate sobre os limites para 
a aplicação do princípio da precaução, além de, sem a pretensão de esgotar o tema, apontar algumas balizas para sua utilização pelo poder público. Diversos tribunais nacionais e internacionais, como o Supremo Tribunal Federal, o Conseil Constitutionnel francês e a Corte Internacional de Justiça, já reconheceram a necessidade de delimitação de balizas claras para alinhar o princípio da precaução ao seu núcleo legitimador.

Importa registrar, inicialmente, que as medidas de precaução devem ser aplicadas nas situações concretas em que seja constatado risco ao meio ambiente e à saúde humana e desde que esse risco possa ser caracterizado como grave e irreversível. Não sendo identificado o risco ou, mesmo se identificado, ele não seja considerado grave e irreversível, não incidirão medidas de precaução. Além disso, o critério do risco não pode estar dissociado dos demais elementos e/ou pressupostos que norteiam a própria definição do princípio.

Presentes os pressupostos de aplicação da precaução, a sua incidência ao caso concreto deve observar os requisitos da proporcionalidade e da razoabilidade. A Administração Pública, sobretudo nos casos em que dispõe de espaços de discricionariedade em suas decisões, jamais pode se afastar da vedação de excesso.

Não se pode olvidar que as decisões do poder público, especialmente aquelas calcadas no princípio da precaução, devem ser motivadas e fundamentadas, analisando expressamente a verossimilhança das alegações de incidência de riscos graves e irreversíveis decorrentes das atividades antrópicas. É inadmissível uma decisão, seja ela administrativa ou judicial, fundada apenas em alegações levianas que tenham hipóteses de causalidade estabelecidas por via dedutiva. Análises que flertam com o abstrato e que propõem exercícios de antecipação a longo prazo guardam relação com o princípio da responsabilidade, e não com o princípio da precaução.

Em respeito ao princípio democrático, as restrições a atividades e tecnologias fundamentadas no princípio da precaução devem ser periodicamente avaliadas. A análise dos riscos ao meio ambiente não deve conduzir a uma decisão imutável e definitiva. As descobertas científicas revestem-se do manto da transitoriedade.

Conclui-se que todos os fundamentos de validade das opções discricionárias devem ser observados nas decisões administrativas ou judiciais que tenham o princípio da precaução como fundamento nuclear, sob pena de promover insegurança jurídica e subjetividade das decisões e 
suscitar controle, interno e externo, nas esferas competentes.

\section{REFERÊNCIAS}

ANTUNES, Paulo de Bessa. Princípio da precaução no direito ambiental brasileiro. Revista Veredas do Direito, Belo Horizonte, v.13, n.27, p.6388 , setembro/dezembro de 2016.

BECK, Ulrich. Risk Society: towards a new modernity. London: Sage Publications, 2008.

BOISSON DE CHAZOURNES, Laurence. La mise en $\square$ uvre du développement durable; 1999.

BRASIL. Supremo Tribunal Federal. Recurso Extraordinário 627.189/SP. Relator: Dias Toffoli.Diário da Justiça, Brasília, 08 junho 2016.

CANOTILHO, José Joaquim Gomes. Direito Constitucional e Teoria da Constituição. $7^{\mathrm{a}}$ ed. 2003.

COMISSAO EUROPEIA. Comunicação da Comissão relativa ao princípio da precaução. Bruxelas, 2.2.2000 - COM (2000) 1 final, disponível em https://eur-lex.europa.eu/legal-content/PT/TXT/PDF/ ?uri=CELEX:52000DC0001\&from=PT, acesso em 03 dez 2013.

EWALD, François. Philosophie de la précaution. L'annéesociologique, $\mathrm{n}^{\circ}$ 46. Paris: P.U.F., 1996.

FRANÇA. Conseil-Constitutionnel. Jun 2014: La Charte de l'environnement de 2004. Disponível em: <http://www.conseilconstitutionnel.fr/conseil-constitutionnel/francais/a-la-une/juin-2014la-charte-de-1-environnement-de-2004.141685.html>Acesso em: 04 jul. 2018.

FREITAS, Juarez. O Controle dos atos administrativos e os princípios fundamentais. São Paulo: Malheiros, 2004.

FREITAS MARTINS, Ana Gouveia e. O princípio da precaução no direito do ambiente. Lisboa: AssociaçãoAcadêmica da Faculdade de 
Direito, 2002.

GULLET, Warwick. The precautionary principle in Australia: Policy, Law \& Potential Precautionary EIAs. Risk: Helath, Safety \& Environment. 2000.

JONAS, Hans. O princípio responsabilidade: ensaio de uma ética para a civilização tecnológica; tradução do original alemão Marijane Lisboa, Luiz Barros Montez. Rio de Janeiro: Contraponto: Ed. PUC-Rio, 2006. JUSTEN FILHO, Marçal. Curso de direito administrativo. São Paulo: Saraiva, 2006.

MARCIANO, Alain; TOURRÈS, Bernard. Regards critiques sur le principe de précaution. Paris: Librairie Philosophique J. Vrin, 2011.

MATA DIZ, Jamile Bergamaschine; SANTOS, Luisa A. Cardoso dos. A aplicação do princípio da precaução na jurisprudência brasileira. In: MATA DIZ, Jamile Bergamaschine; DEL POZO, Carlos Francisco; MOLINA, Jose Antonio Moreno. La jurisprudencia ambiental en Iberoamerica. Belo Horizonte: Arraes, 2016.

MILARÉ, Édis. Direito do Ambiente. São Paulo: Revista dos Tribunais, 2015.

NAÇÕES UNIDAS. Declaração do rio sobre meio ambiente e desenvolvimento - 1992. Disponível em: <http://www.onu.org.br/rio20/ img/2012/01/rio92.pdf $>$. Acesso em: 03 ago. 2013.

NAVES, Bruno Torquato de Oliveira; SILVA, Marcela Vitoriano e. Organismos geneticamente modificados sob a perspectiva da tutela das gerações futuras. In: Veredas do Direito, Belo Horizonte, v. 11, n. 22. p. 355-380, Julho/Dezembro de 2014.

PARGA Y MASEDA, Patricia Jiménez de. El principio de prevención en el derecho internacional del medio ambiente. Madrid: Ecoiuris, 2001.

SAMPAIO, José Adércio Leite; WOLD, Chris; NARDY, Afrânio. Princípios de direito ambiental. Belo Horizonte: Del Rey, 2003. 
SUNDFELD, Carlos Ari. Fundamentos de direito público. 5. ed. São Paulo: Malheiros, 2012 ( $3^{\mathrm{a}}$ tiragem).

SUNSTEIN, Cass Robert. Laws of fear. New York: Cambridge University Press, 2005.

TOLEDO, André de Paiva; RIBEIRO, José Cláudio Junqueira; THOMÉ, Romeu. Acidentes com Barragens de Rejeitos da Mineração e o Princípio da Prevenção: De Trento (Itália) a Mariana (Brasil). Editora Lumen Juris: Rio de Janeiro, 2016.

THOMÉ, Romeu. Manual de Direito Ambiental. $8^{\mathrm{a}}$ edição, Salvador: Juspodivm, 2018.

THOMÉ, Romeu. O princípio da vedação de retrocesso socioambiental no contexto da sociedade de risco. Salvador.Juspodivm, 2014.

THOMÉ, Romeu; TAVARES, F. H. Os direitos fundamentais como limitadores do poder estatal no Estado Democrático de Direito. In: TAVARES, Fernando Horta. (Org.). Teoria Geral do Direito Público: Institutos Jurídicos Fundamentais sob a perspectiva do Estado de Direito Democrático. 1ed.Belo Horizonte: Del Rey Editora, 2013, v. 1, p. $265-$ 293.

UNITED NATIONS DEVELOPPEMENT PROGRAM. Le Protocole de Montréal relatif à des substances qui appauvrissent la couche d'ozone. Préambule. Disponível em: <http://ozone.unep.org/new_site/fr/Treaties/ treaties_decisions-hb.php?nav_id=6> Acesso em: 23 jul. 2013.

WOLFRUM, Rüdiger. O princípio da precaução. In: VARELLA, Marcelo Dias; PLATIAU, Ana Flávia Barros. Princípio da precaução. Belo Horizonte: Del Rey, 2004. p. 13-28.

WORLD TRADE ORGANIZATION. EC-Hormones. WT/DSB/M/42, adopted on 23 February 1998. Acesso em: <docsonline.wto.org/imrd/ directdoc.asp?DDFDocuments/t/WT/DS/26ABR.WPF.> Acesso em 25 de março de 2013. 
VARELA, Isabela Dalle; ZINI, Júlio César Faria. Energias renováveis: meio ambiente e sustentabilidade.In: CUSTÓDIO, Maraluce M. Energia e Direito: perspectivas para um diálogo de sustentabilidade. Rio de Janeiro: Lumen Juris, 2015, p. 41-58.

Artigo recebido em: 13/07/2018. Artigo aceito em: 25/07/2018.

\section{Como citar este artigo (ABNT):}

SILVA, R. F. T.; DIZ, J. B. M. PRINCÍPIO DA PRECAUÇÃO: DEFINIÇÃO DE BALIZAS PARA A PRUDENTE APLICAÇÃO. Veredas do Direito, Belo Horizonte, v. 15, n. 32, p. 39-66, mai./ago. 2018. Disponível em: <http://www.domhelder.edu.br/revista/index.php/veredas/ article/view/1317>. Acesso em: dia mês. ano. 